Peshawar Journal of Psychology and Behavioral Sciences, 2015, Vol. 1, No. 1, 33-45

\title{
Workplace Sexual Harassment in Non- Governmental Social and Development Sector a Case Study of District Peshawar, Pakistan
}

\author{
Salman Jalal ${ }^{1}$, \\ Institute of Management Sciences, Peshawar \\ Fahad Shah', Alamgeer Khan ${ }^{3} \&$ Waheed-Ullah ${ }^{4}$ \\ The University of Agriculture Peshawar
}

\begin{abstract}
The present study was designed to study sexual harassment, which concerns mainly with women at workplace and the reasons behind this harassment. The data were collected from different developmental organization INGO's and NGO's through a questionnaire. The sample of the study comprised of one hundred and eighty two $(\mathrm{N}=182)$ women working at different organizations with minimum experience of four years or above. The findings of the present study revealed that organizational ethics and attractiveness were found to be positively and significantly associated with sexual harassment at workplaces whereas the study showed reveal that familiarity with organization harassment policy was negatively associated with sexual harassment at workplaces. Open sitting or sitting in organizations with shut doors were not significantly associated with sexual harassment at workplace. It was concluded from the findings of the present study that organizational ethics play a a highly significant role in sexual harassment against working women.
\end{abstract}

Keyword. Harassment, women, government, NGO, ethics, attraction

\footnotetext{
${ }^{1}$ Lecturer, Institute of Management Sciences, Peshawar, Pakistan

${ }^{2}$ Lecturer, Department of Rural Development, The University of Agriculture, Peshawar

${ }^{3}$ Lecturer, Department of Rural Sociology, The University of Agriculture, Peshawar, Pakistan

${ }^{4}$ Lecturer, Department of Management Sciences, The University of Agriculture, Peshawar, Pakistan
} 
Harassment is one of the main issue and most discussed matter worldwide due to its negative impact on the victims, organization and the society itself. Harassment is not linked with both the genders, but most of the research attributes the issues which is majorly concerned with women, who are the victims of harassment in workplace environment (Koss, 1992).

The current study propose to reveal the variety of elements, which might help in minimizing or eliminating the sexual harassment at workplace. The main findings of this research study will help the organizations to identify specific elements, which adhere in minimizing the intensity of sexual harassment at workplace. Furthermore the study will also identify some hidden elements at workplace, which are needed to avoid sexual harassment and to maintain healthy working environment for workers particularly women serving in organizations.

One of the important tasks for all managers is to manage sexual harassment at workplace because if it once occurred, can cause serious physical and psychological problem for the harassed employees and can also affect the image of organization in form of financial loss and bad reputation (Louise, Charles, Michele and Vicki, 1997). In Pakistan, sexual harassment is experienced at workplaces in different forms like molestation, unwanted physical contact, gestures and unwanted comments (Anila, 1998). Due to serious nature of the issue, different voices in the country forced the Pakistan's government to promulgate law against sexual harassment at workplaces, which resulted in the year 2010 in the form of "Protection against Harassment of women at workplace". Now this law is in force in Pakistan but still sexual harassment remains a common complaint especially for females. To safeguard the concerns of these working females at Pakistan's workplaces it is required to explore such elements which either enhancing or deterring the level of sexual harassment at work place.

\section{Defining Sexual Harassment}

In general terms, Sexual Harassment is defined as any behaviour which is of sexual nature and not welcomed. The difficult task in explaining sexual harassment is the term "unwelcome behaviour". (Smit and Du Plessis, 2011). 
There is no globally agreed list of defined unwelcome behaviours, because the list of unwelcome behaviours may vary from culture to culture. A behaviour (gesture or action) acceptable at one place or is thought to be enjoyable at workplace for creating fun and harmony among workgroups like flirting, joking, etc. might be considered as an act of sexual harassment in another place or culture. Around the globe, sexual harassment is considered as behaviour or conduct of sexual nature, which is unwelcomed and has hostile, humiliating, offensive effects. (Lacey, 2012)

Pakistani Law has given the following definition of sexual harassment: "Any unwelcome sexual advance, request for sexual favours or other verbal or written communication or physical conduct of a sexual nature or sexually demeaning attitudes, causing interference with work performance or creating an intimidating, hostile or offensive work environment, or the attempt to punish the complainant for refusal to comply to such a request or is made a condition for employment." (Lari and Zaman, 2011)

\section{Characteristics and Manifestations of Sexual Harassment}

Sexual harassment behaviours can be largely classified in to two main forms, one is physical form and generally considered to be relatively serious than the other form which is nonphysical. Physical form is the one in which physical contact is established in the sexual behaviour, that physical contact can be in any form. Nonphysical behaviour includes insulting any one, making offensive comments, offensive gestures or referring to any material which is vulgar or offensive in any form. Different research revealed that unlike the general perception of considering physical harassment as serious one relatively to nonphysical harassment, studies shows that verbal, emotional, nonphysical harassment can result in more serious problems than the physical form. (Saunders, Huynh and Goodman, 2007).

According to different studies around the globe, $85 \%$ of cases of sexual harassment are reported by women against men, whereas only $15 \%$ were such cases which were reported by men against women harasser (Firestone and Harris, 2003). Studies also reveals that sexual harassment is more experienced in the occupations which are male dominant at large comparing to such occupations which are broadly

Peshawar Journal of Psychology and Behavioral Sciences, 2015, Vol. 1, No. 1, 33-45 
dominated by female or gender-balanced (J Gruber, 1998). Another important aspect is that increased likelihood of sexual victimization is not directly associated with the sex ratios within the organizations, rather it is about male dominancy within the hierarchal settings of the organizations (L Chamberlain and M Crowley, 2008). Similarly, research has also revealed that sexual harassment is more correlated with the culture of the organizations. Sexual harassment experiences are high in organizations where culture is more focus on the performance or job only, where organizations are less sensitive towards the balance of work rather than the culture of making employee their priority and matter of concern. (Handy, 2006).

Various behaviours are characterized as sexual harassment, like telling a dirty joke, staring someone, flirting, teasing, touching, asking about some one's sexual history, making unwanted facial expressions, sharing unwanted emotions etc. (Harris and Anglin, 1998).

\section{Importance \& Objectives of the study}

Focus of the study is to investigate those common elements which exposes female staff to sexual harassment at workplace. Main concern is to find the correlation and its significance with the following four elements.

Attractiveness

Office setup

Organizational Policy

Work ethics

\section{Hypotheses}

1. Females who are more attractive and who perceive themselves more attractive experience more sexual harassment at work place.

2. Females having privacy in office setup will not experience more workplace sexual harassment.

3. Females who possess knowledge about organization policy regarding sexual harassment will be equally prone to experiencing harassment at workplace. 
4. Females working at work places where work ethics are highly emphasized will not be less prone to experience sexual harassment.

\section{Method}

\section{Sample}

The sample consisted of two hundred and sixteen $(\mathrm{N}=182)$ women working in the offices of various organizations in Peshawar.

\section{Tools}

Sexual Harassment Experience Questionnaire (SHEQ), developed by Gelfand, Fitzgerald, and Drasgow's (1995). Gender Harassment, sexual coercion and unwanted sexual attention are the three dimensions on which SHEQ was developed. Five types of sexual harassment by Till (1980) are based on these three dimensions on which SHEQ was developed. Several researches around the globe conducted through SHEQ and the results of those studies suggest that SHEQ possesses sufficient reliability and validity for research use. Anila (1998) reports that to understand the experiences of sexual harassment at workplace by women, SHEQ may be very useful. It may also play a vital role in formulation of interventions developed to limit harassing behaviours at workplace.

\section{Procedure}

Primary data was collected for the study through adopted survey questionnaire from approximately 215 questionnaires were distributed among female staff working in non-governmental social and development sector in Peshawar. Out of 215 distributed questionnaires, 182 filled questionnaires were returned, this makes response rate for the research as $84.65 \%$. Keeping in view the sensitive nature of shared information through survey and the comparatively conservative nature of the society in general, the response rate for the survey was very good. Data of sample respondents was analyzed by SPSS. 


\section{Results}

Table 1

Demographic Profile of Respondents

\begin{tabular}{llc}
\hline Demographic variable & Categories & Percentage \\
\hline \multirow{2}{*}{ Age in years } & $21-30$ & $54.4 \%$ \\
& $31-40$ & $45.1 \%$ \\
& $41-50$ & $0.5 \%$ \\
\hline \multirow{3}{*}{ Marital Status } & Married & $41.8 \%$ \\
& Un-Married & $54.9 \%$ \\
& Divorced & $2.7 \%$ \\
Education & Widow & $0.5 \%$ \\
& Bachelor & $30.2 \%$ \\
& Masters/M-Phil & $68.7 \%$ \\
Experience in years & Others & 1.1 \\
& $1-3$ & 38.5 \\
& $4-6$ & 51.6 \\
Job-status & $7-10$ & 7.7 \\
& 10 or more & 2.2 \\
& Clerical & 23.1 \\
& Officer & 73.1 \\
& Executive & 1.1 \\
\hline
\end{tabular}

Table 2

Frequency of Harassment

\begin{tabular}{lcc}
\hline & F & Percent $(\%)$ \\
\hline Never Harassed & 13 & $7.1 \%$ \\
Harassed & 169 & $92.9 \%$ \\
Total & 182 & $100.0 \%$ \\
\hline
\end{tabular}

Peshawar Journal of Psychology and Behavioral Sciences, 2015, Vol. 1, No. 1, 33-45 
Table 02 shows that $7.1 \%$ of the total respondents revealed that they had never experienced sexual harassment at their work places, where as $92.9 \%$, which makes 169 out of total of 182 respondents revealed that they had experienced sexual harassment at their workplaces. It should be noted that respondents were asked seventeen (17) different questions regarding experience of sexual harassment and were asked to respond at different scales. Statistics of table 02 doesn't mean at all that all of 169 female workers had experienced same kind of sexual harassment with same intensity but it does mean that all of them experienced it but some of them experienced it very rarely and the others did it many times.

Table 5

Predictors of Sexual Harassment

\begin{tabular}{|c|c|c|c|}
\hline Variable & $\mathrm{B}$ & $\mathrm{SE}(\mathrm{B})$ & $\mathrm{B}$ \\
\hline Constant & .861 & .283 & \\
\hline Org.ethics & .281 & .060 & $.324 * * *$ \\
\hline Familiarity & -.090 & .044 & $-.137 *$ \\
\hline Open sitting & -.006 & .065 & -.008 \\
\hline Shut door & -.007 & .034 & -.018 \\
\hline Attractiveness & .061 & .018 & $.242 * *$ \\
\hline $\mathrm{R}^{2}$ & .232 & & \\
\hline $\mathrm{F}$ & 10.61 & & \\
\hline
\end{tabular}

Table 5 shows predictors of sexual harassment at workplace. The result shows that organizational ethics and attractiveness are strong predictors of sexual harassment. There is a correlation between the variables but this correlation is not so strong, whereas familiarity with work ethics and organizational policy of sexual harassment is negatively associated with sexual harassment. Open sitting and shut doors are negatively associated with harassment, but are not significantly associated with harassment. The value of $\mathrm{R}$ Square, which is .232, shows that $23.2 \%$ of the dependent variable can be explained by independent variables. Autocorrelation is depicted by the value of Durbin-Watson. In 
this case the value is 1.915 , which is close to 02 , it shows that there is no autocorrelation between the variables.

\section{Discussion}

Sexual harassment is an issue of interest of many researchers. The aim of the study was to investigate the predictors of sexual harassment against women working in different organizations. The results revealed that organization ethics, familiarity of organizational sexual harassment policy and attractiveness are significant at $\mathrm{p}<.05$, whereas office sitting setup is not significant. The results showed that the organizational working ethics had significant relationship with the sexual harassment experiences, So the result shows that females working in offices where work ethics are highly emphasized will experience less sexual harassment.

The beta value (Beta $=-.137$ ) is regarding the hypothesis of familiarity or knowledge of female staff regarding their organizational policy of sexual harassment. The relationship is significant but negative value of beta depicts that the significance is in opposite direction. Which means that higher the knowledge of organizational sexual harassment Policy will result in less experiences of sexual harassment. So female who possess more knowledge about organizational sexual harassment policy will experience less sexual harassment.

The beta value (Beta $=.242$ ) tells that the element of attractiveness is highly significant to the experiences of sexual harassment. Our hypothesis was that female who are attractive or who perceive themselves as attractive will not experience more sexual harassment, but results shows that attractive female or the one who perceives that they are attractive, will experience more sexual harassment at their workplaces.

The fourth element of this study was office sitting setup was not significant, which means that experience of sexual harassment has nothing much to do with the sitting of female staff either in shut door office or in visible area.

\section{Conclusion \& Recommendations}


The study was based on four factors (elements) and their relationship with sexual harassment at workplace. The main aim was to investigate the significance of the relationship among elements and experiences of sexual harassment at workplace. The study was based on the information collected through survey questionnaire which was adopted from Sexual Harassment Experience Questionnaire (SHEQ) from 182 female working in non-governmental social and development sector in Peshawar. Firstly, the study suggests that the female workers who are attractive or perceives that they are attractive are having greater risk of experiencing sexual harassment at their workplaces. In our opinion the reasons might be the fact that female who considers themselves attractive will try to dominate among workers or will try to be favorite, which exposes them more and becomes a motivational factor for the perpetrator. Secondly, the study suggests that the knowledge of organizational policies regarding sexual harassment minimizes the risks of sexual harassment at workplace for female. The more the female staff having knowledge of their organizational policies, the lesser will be the chance for them to be exposed to sexual harassment. The reason can be the fact that knowledge regarding policies makes the female aware of the sexual harassment and gives them the confidence and gives them feelings that the organizations have zero tolerance for sexual harassment. Thirdly, the study suggests that professional environment where work ethics are emphasized, discourages the work place sexual harassment. Furthermore, the study suggests that privacy at office setup does not play a major role in aggravating or limiting the workplace sexual harassment.

While interpreting the results, do consider the fact that the questions, which were asked from female respondents were very sensitive and bold in nature, keeping in view the cultural context of Peshawar, Pakistan. So it was very difficult to get more detailed and clear picture of their experiences regarding sexual harassment at workplace. Another important aspect is that it is not necessary that only these factors which the study suggests limits or aggravate the sexual harassment at workplace, there can be more significant factors but as our study was limited to these four factors that is why the conclusion is drawn on these four elements only. Lastly, keep this in consideration that most of the questions asked in the survey was regarding their past experiences, so memory was involved and the respondents were asked to 
recall their experiences from the past, which might create possibility of not remembering exactly all the situations.

It is recommended that longitudinal study can be more fruitful in this regard, whereas data from the same respondents is collected at different time frame. It is also recommended that such studies need to carry out in different sectors of Pakistan, because studies in different sectors can reveal different results because of the nature and environment of work. It is a reality that despite the sexual harassment acts and laws are present in Pakistan and within the organizations but these laws are relatively in their early stages and still a lot more to be done in the enforcement of such laws to discourage workplace harassment.

Organizations needs to give due importance to the issue in their own domain, they need to aware their staff of such issues and educate them regarding their policies. Male employee needs to be conveyed clearly regarding the penalties of such acts and fear needs to be created in their mind regarding negative consequences if they are involved in sexual harassment at workplace. There is need to educate and train the female staff regarding their response in case of experiencing sexual harassment and they should be encouraged to report such cases so that strict actions can be taken to prevent or minimize such cases in the future.

\section{References}

Alaimo, K. (2016). Increased Efforts by Modern States to Improve their Reputations for Enforcing Women's Human Rights. International Journal of Communication, 10, 20.

Anila, 1998.Sexual Harassment at workplaces and coping strategies employed by women. Department of Psychology. Islamabad, Quaid e Azam University. PhD: 209.

Chamberlain, L. J., Crowley, M., Tope, D., \& Hodson, R. (2008). Sexual harassment in organizational context. Work and Occupations, 35(3), 262-295.

Committee on the Elimination of all forms of Discrimination Against

Women, General Recommendation 19 (1992), para 
Workplace Sexual Harassment in Non-Governmental Social .....

18.athttp://www.un.org/womenwatch/daw/cedaw/recommendati ons/recomm.htm (viewed 23 March 2015).

Firestone, J. M., \& Harris, R. J. (2003). Perceptions of effectiveness of responses to sexual harassment in the US military, 1988 and 1995. Gender, Work \& Organization, 10(1), 42-64.

Goldberg, P., \& Kelly, N. (1993). International Human Rights and Violence Against Women.

Government of Pakistan, (2010). The protection against harassment of women at the workplace act 2010. Islamabad, Pakistan.

Gruber, J. E. (1998). The impact of male work environments and organizational policies on women's experiences of sexual harassment. Gender \& Society, 12(3), 301-320.

Handy, J. (2006). Sexual Harassment in Small-Town New Zealand: A Qualitative Study of Three Contrasting Organizations. Gender, Work \& Organization, 13(1), 1-24.

Harris, M., \&Anglin, J. (1998). Trauma recovery and empowerment: A clinician's guide for working with women in groups. Simon and Schuster.

Hunt, C. M., Davidson, M. J., Fielden, S. L., \& Hoel, H. (2010). Reviewing sexual harassment in the workplace-an intervention model. Personnel review, 39(5), 655-673.

Koss, M. P. (1993). Detecting the scope of rape a review of prevalence research methods. Journal of interpersonal violence, 8(2), 198222.

Lari, M. Z., \& Zaman, S. (2011). Sexual Violence \& the Law in Pakistan. Karachi: War Against Rape.

Mahmood, Q. K., \& Ahmad, I. (2010). Perception of sexual Harassment at workplace, knowledge and attitude of working women towards workplace Harassment Act 2010. Social Sciences Review of Pakistan, 22.

Nauman, B., \&Abbasi, A. S. (2014). Sexual Harassment at Workplace A Case of Banking Sector in Lahore. Middle-East Journal of Scientific Research, 20(5), 558-566 
Saunders, P., Huynh, A., \& Goodman-Delahunty, J. (2007). Defining workplace bullying behaviour professional lay definitions of workplace bullying. International journal of law and psychiatry, 30(4), 340-354.

Smit, D., \& Du Plessis, V. (2011).Sexual harassment in the education sector. PER: Potchefstroomse Elektroniese Regsblad, 14(6), 172217.

Lacey, H. (2012). Powerful Win Win Solutions: A practical toolkit for resolving conflict in the workplace. Author House

llivan, D. J. (1994). Women's human rights and the 1993 World Conference on Human Rights. The American Journal of International Law, 88(1), 152-167. 